\title{
Bring the Change You Want to See: Scripting Women and Girls into India's Urban Sanitation Actions
}

\author{
Arundati Muralidharan, Myles F. Elledge, Suneeta Krishnan, \\ Miriam Hartmann, and Brent Rowe
}

The Government of India's focus on "Swachh Bharat" (Clean India) brings renewed commitment and momentum to address the country's sanitation crisis. The national government's initiatives promise to improve sanitation coverage and end open defecation, conferring benefits in terms of health, education, and even women's safety. ${ }^{1}$

India is on the cusp of having half of its population live in urban areas, a transition that heralds greater economic development and prosperity for many. Yet the abysmal urban sanitation situation threatens to undermine such gains. One in every six Indians lives in an urban slum where grossly deficient urban infrastructure and limited basic service planning do not provide adequate sanitation. ${ }^{2}$ Therefore, despite improvements in sanitation infrastructure in select urban pockets, an estimated $12.6 \%$ of urban residents continue to defecate in the open. Sewer connections, while growing in number, are still inadequate. ${ }^{3}$ The extremely low rate of sewage treatment in the country is fouling drains and water bodies. India's Central Pollution Control Board estimates show that $75 \%$ of water pollution by volume is from urban sewerage, and even where urban waste is piped, less than $15 \%$ of the waste that makes it into a pipe is actually treated before it is discharged. 4 The urban poor bear the greatest impact of poor sanitation, particularly in terms of their health, with women and girls facing additional challenges related to menstrual hygiene, gender-based violence, and discontinuing education.

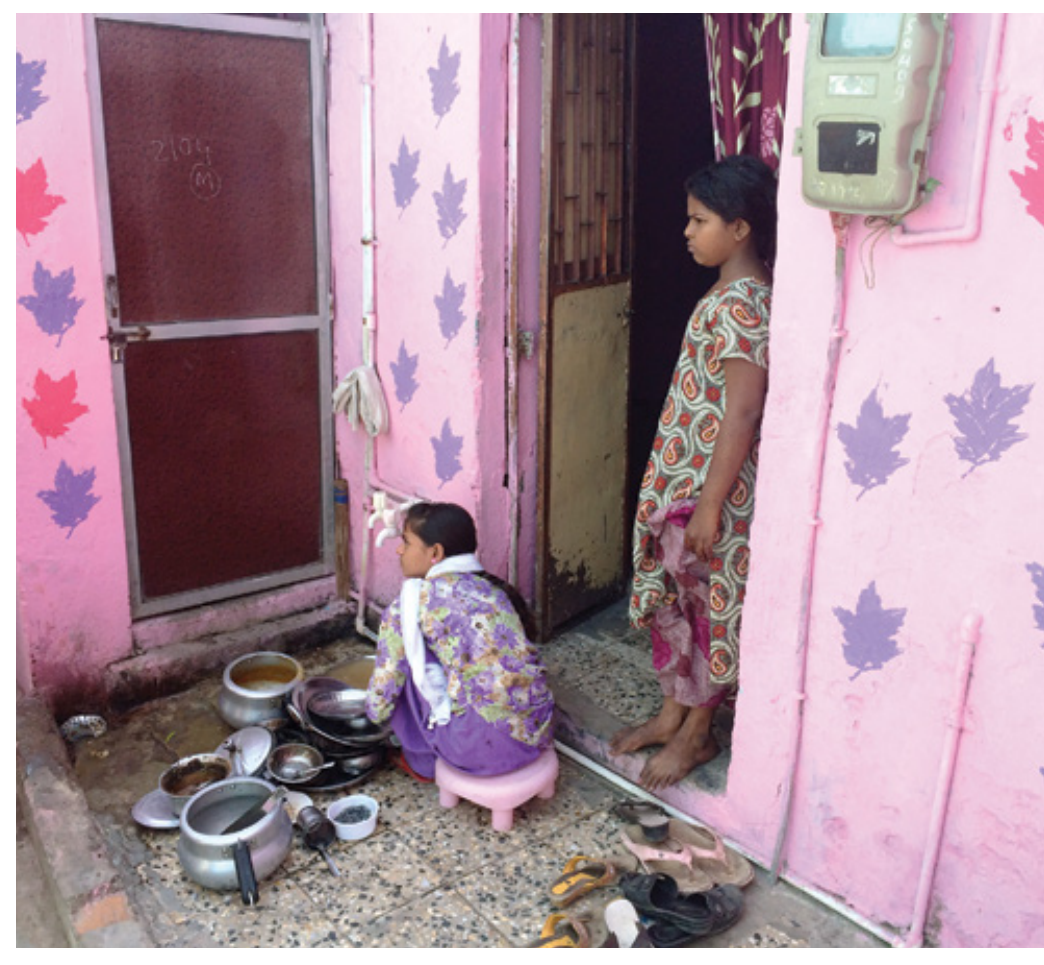

\section{The Sanitation Priority}

- Nearly $60 \%$ of the world's open defecation occurs in India.

- Consequences of poor sanitation are devastating on human health, education, the environment, and the economy in general.

- Women and girls face particular risks due to poor sanitation facilities.

- Improved sanitation facilities include a connection to a public sewer or septic tank, pour flush latrine, simple pit latrine, or ventilated and improved pit latrine. 
Men and women have specific sanitation needs, access, and utilization patterns and experiences. Poor sanitation facilities and services affect both sexes, but women and girls are particularly vulnerable due to a loss of dignity, increased health concerns, and safety risks as elucidated below.

- Sanitation and menstruation: Menstrual hygiene management (MHM) represents an equity, human rights, health, and environmental issue closely linked to sanitation. ${ }^{5}$ Girls' and women's ability to manage their menses is undermined by poor sanitation facilities that do not afford adequate privacy and space, as well as water, toilet, and hygiene amenities to change, wash and dry, and dispose of used menstrual absorbents and to maintain personal hygiene. 6

- Sanitation and nutritional impacts: Evidence is limited, but organizational reports and anecdotal evidence suggest that girls and women control their food and water intake to limit defecation and urination to certain times of the day when they can defecate in the open (usually at night or early morning) or use available toilet facilities when most convenient. ${ }^{7}$ Such practices may affect female nutritional status and may also result in urinary tract infections, constipation, and other urogenital and gastric problems. ${ }^{7}$ Implications for adolescent girls and pregnant women are particularly important, given the nutritional needs during these life stages.

- Sanitation and education: Quality sanitation facilities are a factor in school enrollment and retention, especially for secondary education among postmenarcheal girls.8.9 Lack of toilets, disposal mechanisms for used menstrual absorbents, and privacy make it difficult for girls to manage their menses in school.

- Sanitation and gender-based violence: Poor sanitation access can enhance women's vulnerability to gender-based violence. ${ }^{7}$ Lack of toilets leads to open defecation practices that may put women and girls at risk for harassment and attack. At times, existing facilities may be unsafe, lacking adequate lighting, doors that lock, and other security measures that can enhance women's susceptibility to genderbased violence. $^{7}$

- Sanitation and well-being: Psychosocial effects associated with open defecation and negative experiences of toilet use include stress, anxiety, fear, disgust, low self-confidence, and low self-esteem. Women and girls also express unique concern over stigma and discrimination related to the experience of violence or harassment or being seen defecating or urinating in the open, fear of being blamed for being assaulted or harassed, being accused of being unfaithful, and disowned by families if they experience sexual harassment as a result of open defecation or as a result of using public toilets. ${ }^{10}$ Fear was highlighted by women in urban, low-income settlements as the foremost concern in relation to toilet use and open defecation. This fear alone can preclude women's toilet use even when toilets are available. 10

Sanitation facilities and services in India, and the lack thereof, result in significant disadvantages in terms of health, education, safety, and well-being for girls and women. Moving forward, sanitation policies and programming must ensure that effective sanitation facilities and services are designed to account for these gender-specific needs. ${ }^{11,12}$ This policy brief aims not only to draw attention to the unique sanitationrelated challenges that girls and women face, but also to examine how government sanitation initiatives in urban areas recognize and address these challenges.

\section{Gender Dimensions of India's Sanitation Policies}

This section examines six major Government of India, urban-related initiatives to highlight how each addresses the gender dimensions of sanitation. These six nationallevel initiatives represent the Government of India's largest initiatives since 2010 that have direct and indirect operational goals to affect urban sanitation. The review looks at "policies" and their implementation guidelines, as well as "missions" and their goal-oriented, time-bound components. Policies and missions are important to evaluate because they denote commitment, articulate priorities, and motivate the allocation of resources for implementation. National policies are also valuable to stimulate incentives and promote local actions. Table 1 presents the six initiatives, identifying the time frame, institutional leadership, primary drivers, core objectives, and modalities; the table also defines recommendations on how the gender differences of women are often missing from the initiatives and could be better incorporated. Although some of the initiatives have expired, it is instructive to see how these frameworks could be strengthened to achieve better targeting.

The six policy and mission initiatives reviewed here have been or are implemented by different government bodies, many of which direct their efforts toward improving urban development and urban service delivery, with the intent to benefit the urban poor. The overarching emphasis across these initiatives is infrastructure development, improvement, or both. Behavior change, education, and sanitation advocacy are mentioned but receive less attention and are inadequately operationalized. Gender considerations, primarily women's sanitation-related needs, are nominally mentioned in policy documents, with insufficient explanation or guidance on how their needs will be met by these initiatives, especially menstrual hygiene and gender-based violence. 


\section{Table 1. Overview of sanitation-related policies and missions for urban India}

\section{Policy, Dates, and Lead Ministry} Key Driver

National Urban Sanitation Policy (NUSP)

2008-2015

Ministry of Urban Development
Urban sanitation; vision is for urban areas in India (both cities and towns) to become "totally sanitized," emphasizing health, wellbeing, and environmental benefits through sanitation facilities that are affordable
Objective(s) and Modalities

Behavior change and education; end open

- Development of city sanitation plans

- Seven core principles guide planning efforts: (1) institutional roles and responsibilities; (2) awareness generation; (3) city-wide approach; (4) technology choice; (5) reaching the underserved; (6) client focus and demand generation; and (7) sustained improvements

Highlights women as a vulnerable group, but silent on women-specific, sanitation-related needs defecation; city-wide sanitation

Gender and Sanitation Recommendations

- Require women's engagement in facility design and management

- Create awareness among community members and stakeholders about women's sanitation needs

- Include menstrual hygiene management (MHM) considerations in sanitation planning and installation (particularly bathing and washing facilities and solid waste management of menstrual waste)

- Address gender-based violence link to sanitation through the design of safe and secure sanitation facilities that are easily accessible to girls and women

- Include sex-disaggregated data (e.g., number of toilets for women and men) and gender indicators (e.g., toilets installed in locations considered safe and accessible by women) to enable gender-integrated sanitation planning and implementation

\begin{tabular}{|c|c|}
\hline Jawaharlal Nehru & Slum upgrading and \\
\hline Urban Renewal & urban infrastructure \\
\hline Mission & development; over \\
\hline (JnNURM) & half of India's gross \\
\hline $2005-2014$ & domestic product \\
\hline $\begin{array}{l}\text { Ministry of Housing } \\
\text { and Urban Poverty } \\
\text { Alleviation }\end{array}$ & $\begin{array}{l}\text { comes from cities, and } \\
\text { for continued economic } \\
\text { growth, infrastructure } \\
\text { improvement in urban } \\
\text { areas is essential }\end{array}$ \\
\hline
\end{tabular}

Infrastructure improvements: water, sanitation, solid waste management; service provision to urban poor

- Map women's sanitation needs and identify potential solutions across different types of slums in cities
Rajiv Awas Yojana Urban housing and slum

(RAY)

2013-2022 development; aim is to move toward a "slum-free India"

Two submissions proposed:

- Basic services for the urban poor

- Urban infrastructure and governance

Stipulates that women may have unique sanitation needs, yet vague on the specifics on addressing these needs

Housing improvement, water supply, sanitation, and solid waste management; in collaboration with JnNURM, RAY promotes total sanitation through the provision of individual toilets and water supply to each household and appropriate sewage connections

The program documentation does not outline any gender considerations

- Strengthen solid waste management initiatives in slums to include the disposal and management of menstrual waste

- Include sex-disaggregated data and gender indicators to enable gender-integrated sanitation planning and implementation

- Identify how women's sanitation needs, specifically related to $\mathrm{MHM}$, can be addressed in housing improvement initiatives (e.g., provisions such as dustbins or incinerators to deal with menstrual waste, and provisions for washing and drying reusable menstrual absorbents)

- Coordinate with Swachh Bharat Mission and NUSP to explore opportunities for the construction of individual household latrines and solid waste management under RAY initiatives in different types of slums

\begin{tabular}{|c|c|c|c|}
\hline $\begin{array}{l}\text { National Urban } \\
\text { Health Mission } \\
\text { (NUHM) } \\
2013-2017 \\
\text { Ministry of Health } \\
\text { and Family Welfare }\end{array}$ & $\begin{array}{l}\text { Urban health; aims to } \\
\text { meet the health needs } \\
\text { of the urban poor by } \\
\text { improving health care } \\
\text { services in urban areas } \\
\text { and converging with } \\
\text { initiatives that address } \\
\text { factors outside of health } \\
\text { that influence the health of } \\
\text { urban populations, such as } \\
\text { sanitation }\end{array}$ & $\begin{array}{l}\text { Build health capacity; increase services to all } \\
\text { vulnerable, disadvantaged urban areas; outline } \\
\text { norms for the establishment of directed } \\
\text { health services for the urban poor; focus on } \\
\text { improved public health system, partnerships, } \\
\text { involvement of urban local bodies, and } \\
\text { community engagement in cities with a } \\
\text { population of over 50,000 } \\
\text { Recognizes gender differences in health, but does } \\
\text { not directly address the intersections between } \\
\text { women's and girls'sanitation needs and health }\end{array}$ & $\begin{array}{l}\text { - Advocate for research on how gender-responsive } \\
\text { sanitation planning can improve health (with } \\
\text { a focus on MHM, gender-based violence, and } \\
\text { nutritional effects) } \\
\text { - Advocate for intersectoral convergence to } \\
\text { improve sanitation in urban areas with the intent } \\
\text { to improve health } \\
\text { - Include sex-disaggregated data and gender } \\
\text { indicators to enable gender-integrated sanitation } \\
\text { planning and implementation } \\
\text { - Include indicators that can track the health } \\
\text { impacts of sanitation } \\
\text { - Increase women's participation in urban local } \\
\text { bodies, especially in relation to sanitation } \\
\text { planning and implementation }\end{array}$ \\
\hline
\end{tabular}


Table 1. Overview of sanitation-related policies and missions for urban India (continued)

Policy, Dates, and
Lead Ministry
Nirmal Bharat
Abhiyan
(NBA)
2009-2014
Ministry of
Drinking Water and
Sanitation

Swachh Bharat
Mission (SBM),
Submission for
urban areas
2014-2019
Ministry of Urban
Development
and Ministry of
Drinking Water and
Sanitation

\section{Key Driver}

End open defecation and improve drinking water supply

Sanitation

Objective(s) and Modalities

Gender and Sanitation Recommendations

Behavior change; hygiene education; end open defecation by 2022; household/community toilet provision; ensure water supply; focus on sanitation coverage awareness and hygiene education; installation of sanitation facilities in communities, schools, and Anganwadi centers; and supporting the development of costeffective, sustainable, and environmentally sound sanitation and waste management technologies

NBA is the only program to make explicit references to MHM; a December 2013 modification to NBA guidelines called for the inclusion of hand-washing at critical times and the inclusion of information on maintenance of menstrual hygiene in information education communication materials for all stakeholders; the amendment also called for funding facilities, such as incinerators for MHM in schools, women's centers, and public health facilities

Furthers the goal of NUSP to have "totally sanitized, healthy, and livable cities and towns"
Elimination of open defecation; toilet improvement; eradication of manual scavenging; improved solid waste management; promotion of behavior change; awareness generation; capacity building of urban local bodies; facilitating private-sector engagement for capital expenditure, and operations and maintenance

Key action areas:

- Provision of household toilets

- Community toilets

- Public toilets

- Solid waste management

- Information education communication and public awareness

- Capacity building and administrative and office expenses

No mention of sanitation needs specific to girls and women; no mention of MHM, especially in the context of sanitation infrastructure and solid waste management for urban areas; MHM guidelines for SBM Gramin (rural) have been proposed and are currently under review by the Ministry of Drinking Water and Sanitation
Adapt and apply NBA's plan for including MHM in solid and liquid waste management, as well as NBA's information, education, and communication materials on MHM in urban settings
- Ensure women's participation in the design of household, community, and public toilets

- Include the disposal of menstrual waste products in solid waste management plans

- Spread awareness about actions that respond to women's sanitation needs and gender-responsive sanitation solutions through public awareness campaigns

- Implement monitoring and evaluation plans to evaluate facilities, use patterns, and educational impact for men and women 
Assessments of policy impacts from a gender perspective are lacking. Monitoring formats outlined by policy documents do not recommend the collection of sex-disaggregated data, nor do they gather information on differences among men's and women's utilization of facilities and services provided under these initiatives. In NUSP, for instance, the National Award Scheme for Sanitation for Indian Cities outlines a rating chart for sanitation in cities; none of the indicators is disaggregated by sex, and no gender-sensitive indicators (e.g., women's participation in planning processes or decision making) are included. ${ }^{13}$ The paucity of monitoring and evaluation data that highlight differences by sex and gender indicators undermine policy makers' and program planners' efforts to identify gender gaps in sanitation and service delivery. Policy makers can, however, draw upon recent urban sanitation initiatives that are gender-responsive. The Urban Development and Urban Housing Department of the Government of Gujarat has proposed a sanitation index for the Swachh Bharat Mission and includes output indicators assessing the adequacy of toilets for women and men. ${ }^{14}$ The Chennai Municipal Corporation plans to install she-toilets in 348 locations across the city, based on a survey of where public toilets for women are needed. 15 This initiative is a step to fulfill the sanitation data and infrastructure gaps identified by the Transparent Chennai Project, which presents a publicly available survey format for collecting information on public toilets that could inform policy and program initiatives at the city level.16,17

Tackling the urban sanitation crisis in India will take a combination of bold initiatives testing political will and resource commitments. For these policies and programs to be successful, it is important to be more responsive to gender, unpacking and targeting the sanitation needs of girls and women. Prime Minister Narendra Modi's clarion call to protect and promote women's dignity in relation to sanitation and ensure that toilet facilities are available in schools and communities reflects the government's recognition of the gendered nature of sanitation and a desire to take action to respond to these gaps. Evidence and guidance on how genderresponsive sanitation programming can be carried out in terms of the design, location, and management of sanitation systems can bolster sanitation initiatives across the country. 18 As plans for the Swachh Bharat Mission are solidified and monitoring metrics are defined, sanitation and gender are essential elements to be written in consistently and thoughtfully to promote inclusive solutions to India's sanitation challenge.

\section{Recommendations}

- Urban policies addressing sanitation and explicitly calling for the design and construction of toilets that offer safety and privacy; space, water, and soap to facilitate washing of hands, washing of genitals, and changing of menstrual absorbents; and culturally appropriate disposal of menstrual absorbents.

- Policy guidelines specifying the involvement of women and girls in the design of sanitation solutions, especially in low-income urban settlements and in urban schools.

- Monitoring frameworks in policy documents to include genderresponsive indicators and plans to disaggregate data by sex in order to lay the foundation for gender-responsive sanitation planning and performance monitoring.

- Policy documents advocating for gender-related research on sanitation practices and preferences at the city level to inform policy and program initiatives

\section{References}

1. PTI. Construct separate toilets for girls in schools: Modi. The Hindu. New Delhi; 2014 Aug 15. Available from: http://www.thehindu.com/news/national/constructseparate-toilets-for-girls-in-schools-modi/article 6321025.ece

2. Dasra.org. Squatting rights: access to toilets in urban India. Mumbai; 2012 Sept. Available from: http://www.dasra.org/ pdf/SquattingRights_Report.pdf

3. Government of India, Ministry of Environment and Forests, Central Pollution Control Board. FAQs (frequently asked questions): what are sources of water pollution and wastewater generation scenario? New Delhi; 2013. Available from: http://cpcb.nic.in/faq1.php

4. Government of India, Ministry of Environment and Forests, Central Pollution Control Board. Status of water supply, wastewater generation and treatment in Class-I cities and Class-II towns of India. New Delhi; 2009. Report No.: Control of Urban Pollution Series: CUPS/70/200910. Available from: http://www.indiawaterportal.org/sites/ indiawaterportal.org/files/status_of_water_supply_and_ wastewater_generation_and_treatment_in_class-i_cities_ and_class-ii_towns_of_india_cpcb_2009.pdf

5. WaterAid. We can't wait: a report on sanitation and hygiene for women and girls; 2013. Available from: https://www.unilever.com/Images/we-can-t-wait---areport-on-sanitation-and-hygiene-for-women-and-girls-november-2013_tcm244-425178_1_en.pdf 
6. Sommer M, Kjellen M, Pensulo C. Girls' and women's unmet needs for menstrual hygiene management (MHM): the interactions between MHM and sanitation systems in low-income countries. J Water Sanit Hyg De. 2013;3(3):283-97.

7. House S, Ferron S, Sommer M, Cavill S. Violence, gender and WASH: a practitioners toolkit-making water, sanitation, and hygiene safer through improved programming and services. London: WaterAid/Sanitation and Hygiene Applied Research for Equity (SHARE); 2014. Available from: http://www.susana.org/en/resources/ library/details/2098

8. Birdthistle I, Dickson K, Freeman M, Javidi L. What impact does the provision of separate toilets for girls at schools have on their primary and secondary school enrolment, attendance, and completion? A systematic review of the evidence. London: University of London, Institution of Education, Social Science Research Unit, EPPI Centre; 2011 Jul. Available from: http://r4d.dfid.gov.uk/PDF/ Outputs/SystematicReviews/Birdthistle_et_al_2011.pdf

9. Adukia A. Sanitation and education. Cambridge (MA): Harvard University; 2014.

10. Lennon S. Fear and anger: perceptions of risks related to sexual violence against women linked to water and sanitation in Delhi, India. Briefing Note. London: London School of Hygiene and Tropical Medicine, Sanitation and Hygiene Applied Research for Equity (SHARE); 2011. Available from: www.shareresearch.org/

11. Berna I. India: from alienation to an empowered community_applying a gender mainstreaming approach to a sanitation project, Tamil Nadu. In: Office of the Special Adviser on Gender Issues and Advancement of Women, Department of Economic and Social Affairs, editor. Gender, water, and sanitation case studies on best practices. New York: United Nations; 2006. p. 21-22. Available from: http://www.un.org/esa/sustdev/sdissues/water/casestudies_ bestpractices.pdf

12. UN Water, Water for Life. Gender, water, and sanitation: a policy brief; 2006. Available from: http://www.un.org/ waterforlifedecade/pdf/un_water_policy_brief_2_gender. pdf

13. Ministry of Urban Development. National urban sanitation policy 2008. New Delhi: Government of India; 2008. Available from: http://www.indiaenvironmentportal.org.in/ content/261239/national-urban-sanitation-policy-2008/

14. Government of Gujarat, Urban Development and Urban Housing Department, Mahatma Gandhi Swachhata Mission. Swachhata Index: monitoring cleanliness for government, semi-government and public buildings in Gujarat. Ahmedabad; 2014 Dec 5. Available from: http:// www.umcasia.org/UserFiles/umc/UMC_MGSM\%20 Indicators\%20for\%20building\%20and\%20sites.pdf

15. Chandrababu D. With she-toilets, Chennai shows way in sanitation. Times of India. Chennai: 2014 Jun 16. Available from: http://timesofindia.indiatimes.com/city/chennai/ With-She-Toilets-Chennai-shows-way-in-sanitation/ articleshow/36631664.cms

16. Padmanabhan V, Shekhar S. Chennai's public sanitation challenge. Issue Brief. Chennai: Transparent Chennai; 2012 Nov. Available from: http://www.transparentchennai.com/ chennais-public-sanitation-challenge/

17. Transparent Chennai. Master data sheet public toilets; 2013. Available from: http://www.transparentchennai.com/ master-data-sheet-public-toilets-2013/

18. Hartmann M, Krishnan S, Rowe B, Hossain A, Elledge M. Gender-responsive sanitation solutions in urban India. Research Triangle Park (NC): RTI Press; 2015 Feb. Available from: https://www.rti.org/pubs/genderresponsive_sanitation_solutions_in_urban_india.pdf 
About the Authors

Arundati Muralidharan, DrPH, is a senior research fellow at the Public Health Foundation of India (PHFI).

Myles F. Elledge, M.A., is a senior director of global development and strategy at RTI.

Suneeta Krishnan, PhD., is a social epidemiologist in RTI's Women's Global Health Imperative and an affiliate of the RTI Global Gender Center. She is also technical lead of RTI's India office.

Miriam A. Hartmann, MPH, is a public health analyst in RTI's Women's Global Health Imperative and an affiliate of the RTI Global Gender Center.

Brent R. Rowe, M.A., is a senior economist in RTI's Center for Environmental, Technology and Energy Economics.
RTI Press Research Briefs and Policy Briefs are scholarly essays on policy, methods, or other topics relevant to RTI areas of research or technical focus.

RTI International, 3040 East Cornwallis Road, PO Box 12194

Research Triangle Park, NC 27709-2194 USA

+1.919.541.6000ｒtipress@rti.org www.rti.org

(O2015 Research Triangle Institute. All rights reserved. This document is protected by copyright. Credit must be provided to the author and source of the document when the content is quoted. No part of this document may be reproduced without permission in writing from the publisher. RTI International is a registered trademark and a trade name of Research Triangle Institute.

RTI Press publication PB-0009-1511

www.rti.org/rtipress 